\title{
Karl Marx enfrenta o enigma da produção imaterial
}

Karl Marx faces the enigma of immaterial production

\author{
Rodrigo Moreno Marques*
}

\section{RESUMO}

Este artigo apresenta um contraponto a um dos argumentos centrais da vaga pósmodernista, segundo o qual, na sociedade contemporânea, a lei do valor revelada por Karl Marx teria perdido seu caráter explicativo diante da expansão da produção de bens intangíveis como os conteúdos audiovisuais digitais, ebooks e programas de computadores. Nesse sentido, este artigo tem como objetivo analisar como Marx incorporou em seu arcabouço teórico as dinâmicas socioeconômicas envolvidas na produção imaterial. A análise realizada toma como referências principais os três livros que compõem a obra O Capital - Crítica da Economia Política, além dos manuscritos Teorias da Mais-valia - Volume I e Capítulo VI inédito de O Capital.

Palavras-chave: Produção Imaterial; Trabalho Imaterial; Lei do Valor; Marxismo; Karl Marx.

\begin{abstract}
This paper presents a counterpoint against one of the central arguments of the post-modern wave, according to which, given the expansion of the production of intangible goods (such as digital audio-visual contents, eBooks, and software), the law of value revealed by Karl Marx has lost its explanatory character. In this direction, this paper aims to analyze how Marx incorporated in his theoretical framework the socioeconomic dynamics of immaterial production. The main references for the analysis were the three books that compose Marx's most important work, Capital - A Critique of Political Economy and the manuscripts Theories of Surplus Value - Volume I and Chapter Six (unpublished) of Capital.
\end{abstract}

Keywords: Immaterial Production; Immaterial Labour; Law of Value; Marxism; Karl Marx.

\section{INTRODUÇÃO}

$\mathrm{Na}$ área de Ciência da Informação, estão em expansão pesquisas pautadas pelo pensamento crítico e, mais especificamente, investigações que empregam os aportes da Economia Política clássica e contemporânea para interpretar fenômenos do nosso tempo. Nessa vertente, merecem destaque alguns periódicos nacionais como Liinc em Revista (IBICT) e a Revista Eptic (UFS), assim como periódicos internacionais como o TripeC - Communication, Capitalism \& Critique e o IRIE - International Review of Information Ethics. Esses são alguns exemplos de revistas que têm publicado trabalhos de autores que abraçam os problemas, teorias e categorias da Economia Política, em interlocução com o campo da Ciência da Informação.

\footnotetext{
* Doutor em Ciência da Informação pela Escola de Ciência da Informação da UFMG. Endereço profissional: Endereço: Escola de Ciência da Informação da UFMG, Departamento de Teoria e Gestão da Informação. Av. Antônio Carlos, 6627, Pampulha, CEP 31270901, Belo Horizonte (MG). Email: rodrigomorenomarques@yahoo.com.br
} 
Alguns livros cujos autores pertencem ao campo da Ciência da Informação ou dialogam com a área também trilham percurso semelhante, como as obras Indústria cultural, informação e capitalismo (BOLAÑO, 2000), Informação, Conhecimento e Poder: Mudança Tecnológica e Inovação Social (ALBAGLI, MACIEL, 2011), Trabalho com informação: valor, apropriação, acumulação nas redes do capital (DANTAS, 2012), Revolução 2.0 e a crise do capitalismo global (COCCO, ALBAGLI, 2012), A informação e o Conhecimento sob as Lentes do Marxismo (MARQUES et al., 2014), A dialética do gosto: informação, música e política (SCHNEIDER, 2015), e iKRITIKA: estudos críticos em informação (BEZERRA et al., 2019). Empregando chaves analíticas da Economia Política, esses autores buscam ampliar o alcance do campo da Ciência da Informação para além da sua corrente funcionalista, de natureza operacional, derivada do viés positivista.

Seguindo essa perspectiva, este artigo apresenta um contraponto às abordagens que flertam com o pós-modernismo ao advogarem que, na sociedade contemporânea, a lei do valor revelada por Marx teria perdido seu caráter explicativo diante da expansão da produção de bens intangíveis, a exemplo dos filmes e músicas digitais, ebooks e softwares.

Desde a sua apresentação ao mundo, a teoria do valor de Marx tem sido fonte de controvérsias (PAULA, 1984; MOHUN, 2001). Uma das mais injustas acusações é que os princípios marxianos e suas concepções dariam conta apenas da produção de bens tangíveis feita em fábricas tradicionais, ou seja, produção de mercadorias corpóreas, acumuláveis, que têm existência no tempo e no espaço. Outro argumento dos detratores da lei do valor de Marx reside no fato de que, apesar de a mercadoria intangível consumir um considerável tempo de trabalho para ser concebida e desenvolvida, a reprodução subsequente de cópias digitais desse produto imaterial requer um tempo de trabalho reduzido ou quase nulo. Perante desse fato, alega-se que um dos fundamentos da lei marxiana do valor teria ruído: o tempo de trabalho não seria mais a medida do valor desse tipo de mercadoria.

Diante desses controversos argumentos, este artigo tem como objetivo analisar como Marx incorporou em seu arcabouço teórico as dinâmicas socioeconômicas envolvidas na produção imaterial. Para atingir esse objetivo, são tomadas como referências principais as obras O Capital - Livros I, II e III (MARX, 2013, 2014, 2017), e os manuscritos Teorias da Mais-valia - Volume I (MARX, 1980a) e Capítulo VI inédito de O Capital (MARX, 2004).

Conforme procuro evidenciar neste artigo, o arcabouço teórico do pensador alemão abarca de maneira instigante e inspiradora as relações sociais envolvidas na produção imaterial. Contrariando os postulados pós-modernistas em voga na atualidade, as reflexões de Marx não estão limitadas ao trabalho eminentemente manual empregado, por exemplo, nas indústrias de tecelagem e siderurgia. $\mathrm{O}$ arcabouço marxiano abarca também os trabalhos predominantemente intelectuais, sejam eles executadas dentro do ambiente fabril, como as atividades de engenharia e supervisão, ou fora dele, a exemplo das atividades voltadas para a educação, a cultura, entre outras. Além disso, o autor registrou importantes reflexões sobre a diferença entre o tempo de produção e o tempo de reprodução de um bem.

Este artigo está estruturado em quatro seções. Após a introdução, na segunda seção, são apresentados alguns aspectos do marco teórico de Marx que nos permitem discutir a noção de mercadoria intangível ou mercadoria imaterial, bem como as dinâmicas socioeconômicas envolvidas na produção imaterial. Para construir essa interpretação, são abordadas as seguintes categorias marxianas: força de trabalho, 
capital industrial, indústria de transportes, capital portador de juros, produção imaterial, trabalho produtivo e trabalhador coletivo. Na terceira seção, são apresentados alguns trechos da obra de Marx em que ele argumenta que o valor de uma mercadoria não está associado a seu tempo de produção, mas, sim, a seu tempo de reprodução. Nas considerações finais, apontamos a necessidade de desenvolver reflexões para além dos limites do tempo histórico vivido por Marx, mas sem abrir mão dos seus postulados centrais, pois eles permanecem fundamentais para apreendermos a essência do mundo em que vivemos.

\title{
PARA A CRÍTICA DO PÓS-MODERNISMO: A PRODUÇÃO IMATERIAL NA OBRA DE MARX
}

O objetivo das pesquisas de Marx que deram origem à sua obra magna $O$ Capital foi "investigar [...] o modo de produção capitalista e suas correspondentes relações de produção e de circulação" (MARX, 2013, p. 78). Os três livros que compõem a obra revelam a "anatomia da sociedade civil" (MARX, 2003, p. 4), ou seja, os fundamentos da sociedade burguesa moderna e o modo de produção capitalista que lhe é característico.

\begin{abstract}
Um dos eixos norteadores da narrativa de Marx é a discussão das metamorfoses pelas quais a mercadoria passa ao longo do ciclo do capital. Nessas metamorfoses, assim como em uma odisseia homérica, ao mesmo tempo em que a mercadoria é transformada, ela também transforma o mundo, ou seja, cria o sistema capitalista onde impera a lei do valor (KOSIK, 1976; PAULA, 1984).
\end{abstract}

Antes de apresentar a concepção de mercadoria adotada por Marx, é importante destacar a distinção que o autor estabelece entre a existência social ou funcional da mercadoria e sua existência material. Conforme explica Rubin (1987), ao analisar a sociedade mercantil-capitalista, Marx inovou ao distinguir o processo material de produção e sua forma social. $O$ autor inovou também ao distinguir o processo de trabalho e o processo de formação de valor. Sua ênfase não está nos métodos técnicos e instrumentos de trabalho, mas, sim, na forma social da atividade de trabalho. $O$ que interessa a Marx são as relações de produção entre os indivíduos que tomam parte nos processos produtivos. No modo de produção capitalista, a mercadoria torna-se portadora de relações sociais estabelecidas entre os sujeitos envolvidos na produção e passa a ser mediadora das relações de produção entre pessoas, ainda que essas relações estejam encobertas pelo fetichismo. Assim, a mercadoria desempenha uma função social específica e adquire uma forma social particular. É nesse sentido que Marx (2013) contrapõe a "existência social" da mercadoria, que ele também chama de "existência funcional", à sua "existência material", atribuindo relevância ao primeiro tipo de existência em detrimento do segundo.

Seguindo essa perspectiva, ao empregar os termos mercadoria intangível, mercadoria imaterial, produção intangível e produção imaterial, devemos ter em mente que a mercadoria é depositária de relações sociais e, portanto, o que dá sentido à matéria é o conjunto das relações sociais envolvidas na sua produção (AMORIM, 2018). Além disso, ao adotar essas expressões, é preciso ter clareza que qualquer trabalho humano e o resultado dele derivado, seja esse resultado tangível ou intangível, têm materialidade social (PRADO, 2004). 
Adicionalmente, ao discutir a produção imaterial e o trabalho imaterial, não podemos ignorar o fato de que o trabalho humano não pode ser classificado dicotomicamente como manual ou intelectual. O trabalho de concepção e o trabalho de execução formam uma unidade dialética, tanto no nível do indivíduo produtor, como no nível da produção em larga escala. No plano da produção individual, todo trabalho representa um esforço simultaneamente físico e intelectual. Os trabalhos úteis ou as atividades produtivas constituem, fisiologicamente, funções do organismo humano e "cada uma dessas funções, seja qual for seu conteúdo e sua forma, é essencialmente dispêndio de cérebro, nervos, músculos e órgãos sensoriais humanos" (MARX, 2013, p. 146-147). Nesse sentido, Marx afirma que "o homem isolado não pode atuar sobre a natureza sem o emprego de seus próprios músculos, sob o controle de seu próprio cérebro. Assim como no sistema natural, a cabeça e as mãos estão interligadas, também o processo de trabalho conecta o trabalho intelectual ao trabalho manual" (MARX 2013, p. 577). No âmbito da produção em larga escala, o autor apresenta a ideia de trabalhador coletivo (MARX, 2004, 2013), por meio da qual caracteriza o trabalhador como um agente social complexo e heterogêneo que incorpora os trabalhos de operários, supervisores e engenheiros, atividades que podem ser predominantemente manuais ou intelectuais, mais ou menos qualificadas.

Tendo esses pressupostos em mente, iniciemos a análise da noção marxiana de mercadoria pelos parágrafos iniciais do Livro I de O Capital:

A mercadoria é, antes de tudo, um objeto externo, uma coisa que, por meio de suas propriedades, satisfaz necessidades humanas de um tipo qualquer. A natureza dessas necessidades - se, por exemplo, elas provêm do estômago ou da imaginação - não altera em nada a questão (MARX, 2013, p. 113).

No modo de produção capitalista, prossegue Marx, a mercadoria é a unidade dialética do valor de uso e do valor. O primeiro elemento dessa unidade é facilmente perceptível a todos, pois o valor de uso está voltado para a satisfação das necessidades humanas. Porém, o segundo elemento, o valor, decorre de uma relação social na qual os indivíduos são obrigados a tomar parte como condição para sua sobrevivência. Trata-se de uma relação social não palpável, não acessível aos sentidos humanos. É por isso que a mercadoria é caracterizada pelo autor como uma "coisa sensível-suprassensível" (MARX, 2013, p. 147).

Percebe-se que essa noção de mercadoria apresentada nas primeiras páginas de 0 Capital sugere que a mercadoria seja algo tangível, corpóreo, isto é, "um objeto externo, uma coisa". Em outras palavras, essa definição sugere tratar-se de um objeto externo ao sujeito que o produziu. Além disso, complementa o autor, a mercadoria deve satisfazer necessidades humanas, provenham elas do "estômago ou da imaginação" (MARX, 2013, p. 113) ou, em outros termos, provenham elas do "estômago ou da fantasia" (MARX, 1980b, p. 41).

Podemos notar que, nessas linhas introdutórias de O Capital, ao caracterizar a mercadoria como uma coisa, um objeto externo ao sujeito que o produziu, Marx expõe uma definição de mercadoria que ainda não abarca explicitamente os bens intangíveis, a exemplo de uma apresentação artística ou uma aula, ainda que esse tipo de atividade contemple o segundo aspecto apresentado na definição marxiana, ou seja, ainda que esse tipo de atividade possa satisfazer necessidades provenientes da imaginação ou da fantasia humana.

No entanto, devemos evitar julgamentos apressados. Julgar as concepções marxianas e sua teoria do valor considerando apenas os trechos iniciais do Livro I de O 
Capital, sem seguir o percurso completo dos Livros I, II e III, que nos levam do abstrato ao concreto, seria um desacerto grave. Se esse cuidado tivesse sido tomado por seus detratores, teríamos sido poupados de boa parte dos argumentos infundados daqueles que têm criticado a lei marxiana do valor, inclusive de autores marxistas contemporâneos que fazem coro com discursos pós-modernistas.

Segundo Marx, o "método cientificamente correto" (2011, p. 54) para buscar a "anatomia da sociedade civil" (2003, p. 4) deve tomar com ponto de partida "as determinações universais abstratas, que [...] correspondem mais ou menos a todas as formas de sociedade" (2011, p. 61). Para atingir o real, a construção analítica deve partir do plano abstrato em direção ao concreto, ou seja, a análise teórica deve ser gradativamente enriquecida pelo acréscimo de múltiplos aspectos ou elementos que o autor chama de "múltiplas determinações" (MARX, 2011, p. 54).

Assim, nos capítulos iniciais do Livro I de O Capital, a teoria do valor é apresentada no nível abstrato e, na medida em que o autor avança em sua exposição ao longo dos Livros I, II e III, sua narrativa se aproxima cada vez mais do concreto. Nesse percurso, Marx progressivamente acrescenta em sua análise múltiplas determinações que gradualmente desvelam as formas de aparência do valor e suas dinâmicas contraditórias no modo de produção capitalista. Ao longo do seu percurso expositivo, cada vez mais as categorias ganham novas determinações, novos contornos, novas dimensões, tornando-se mais ricas e complexas.

Essa complexidade crescente fica evidente na medida em que o texto de Marx avança, e o autor passa a adotar uma noção de mercadoria que não está limitada ao rol dos produtos tangíveis. Conforme explica Paula (1984), para Marx a mercadoria pode ser

\footnotetext{
"não só o que é tangível, corpóreo, acumulável, que tem existência no tempo e no espaço, quanto o que não é material, não tem massa e que só existe no tempo: uma execução musical, um espetáculo teatral, uma aula etc." (PAULA, 1984, p. 123).
}

Essa compreensão acerca da natureza da mercadoria enseja a seguinte questão: se, na perspectiva marxiana, a corporeidade não é prerrequisito para existência de uma mercadoria, quais seriam as condições para tal?

Seguindo as reflexões de Marx (2013), podemos afirmar que, para que algo assuma a forma social mercadoria, independentemente da sua "existência material", algumas condições devem ser atendidas: (i) a coisa produzida deve ser fruto do trabalho humano; (ii) deve satisfazer algum tipo qualquer de necessidade humana; (iii) ter sido produzida para o mercado, não para autoconsumo; e (iv) ter sido produzida sob relações capitalistas de produção, onde o trabalho assume uma forma social especificamente capitalista.

Nessa linha, ao refletir sobre a sociedade contemporânea, Cotrim (2012) afirma que o trabalho realizado sob as relações capitalistas de produção e que se objetiva em mercadoria incorpora valor ao valor de uso, independentemente de ele se configurar em produto imaterial, como filmes e softwares, ou ainda em serviços, como educação ou transporte. ${ }^{1}$

\footnotetext{
${ }^{1}$ Apesar de esse entendimento contrariar a opinião de autores como Mandel (1985), Lessa (2005, 2011) e Machado (2015), ele encontra respaldo nas reflexões de outros autores como Paula (1984), Rubin (1987) e Antunes (2018).
} 
Contra incrédulos que poderiam alegar que esse tipo de interpretação se baseia em leituras distorcidas do texto de Marx, podemos destacar primeiramente que ele explicitamente classifica a força de trabalho como uma mercadoria. Segundo o autor, no contexto histórico do capitalismo, a "força de trabalho" ou "capacidade de trabalho" assume a forma social mercadoria. A força de trabalho ou capacidade de trabalho é o "complexo das capacidades físicas e mentais que existem na corporeidade, na personalidade viva de um homem e que ele põe em movimento sempre que produz valores de uso de qualquer tipo" (MARX, 2013, p. 242). Essa mercadoria, acionada por meio do trabalho, é colocada à venda pelo trabalhador nas relações de assalariamento vigentes no modo de produção capitalista. Trata-se de uma "mercadoria específica", algo que não é um objeto externo, mas, sim, um atributo interno do trabalhador. Quando o capitalista compra a força de trabalho por meio de um contrato de trabalho, ele a coloca em movimento e consome seu valor de uso. Esse valor de uso é a realização ou a exteriorização da força de trabalho, isto é, o trabalho que produz mercadorias nas quais está cristalizado ou objetivado o valor. Conforme explica Foley (2001), Marx emprega nesse caso uma noção de mercadoria por analogia e extensão da primeira definição apresentada.

Além disso, no Livro II de O Capital (MARX, 2014), há um trecho que demonstra que a análise marxiana não emprega uma noção de industrialismo limitada à produção de bens fabris-materiais. Nesse manuscrito, Marx adota a expressão "capital industrial" ao apresentar o ciclo completo do capital e, ao fazê-lo, explica que, nessa acepção, o termo industrial abrange todo ramo explorado segundo a lógica capitalista.

Conforme ilustra a fórmula a seguir, o ciclo completo do capital requer, primeiramente, que o dinheiro (D), meio universal de compra e de pagamento, seja investido pelo capitalista para comprar dois tipos de mercadorias (M): a força de trabalho $(T)$ e os meios de produção (MP). Na sequência, está o processo de produção $(P)$ por meio do qual é produzida a mercadoria $\left(M^{\prime}\right)$, que tem seu valor inicial $(M)$ acrescido da mais-valia $(m)$ criada pelo trabalho aí envolvido $\left(M^{\prime}=M+m\right)$. Encerrando o ciclo, surge o dinheiro ( $\left.D^{\prime}\right)$ auferido na venda da mercadoria ( $M$ '), que representa o dinheiro inicialmente investido (D), acrescido de mais dinheiro $(d)$ quando o ciclo se completa $\left(D^{\prime}=\mathrm{D}+d\right)$.

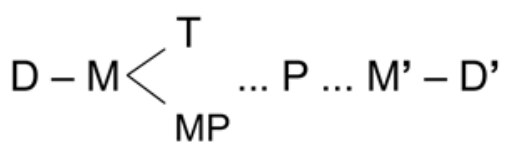

Ao longo desse ciclo, o capital passa por uma série de transformações ou metamorfoses, isto é, mudanças de forma. $O$ valor do capital assume alternadamente as formas capital monetário (capital dinheiro), capital-mercadoria e capital produtivo. Nesse trecho da sua exposição, Marx (2017, p. 131) apresenta uma concepção de "capital industrial" bastante abrangente que sugere que seu arcabouço teórico não está limitado à produção fabril de bens tangíveis:

O capital, que no percurso de seu ciclo total assume e abandona de novo essas formas, cumprindo em cada uma delas sua função correspondente, é o capital industrial - industrial, aqui, no sentido de que ele abrange todo ramo de produção explorado de modo capitalista (MARX, 2014, p. 131).

Exegetas poderiam alegar que essa citação direta tem menor relevância para fins de interpretação do pensamento de Marx, uma vez que ela foi extraída de um 
manuscrito que o autor não publicou em vida e que, portanto, não teria passado pelo seu crivo ou teria sido considerado, pelo próprio Marx, inadequado para publicação. Contra esse tipo de argumento, resgatemos um trecho extraído do Livro I de 0 Capital, onde Marx deixa claro que sua concepção de produção industrial não se limita ao ambiente fabril. Ao abordar os "ramos inteiramente novos da produção" que surgiam em seu tempo, ele classifica como "indústrias" alguns segmentos que não produzem bens tangíveis, a exemplo das comunicações e transportes: "as usinas de gás, o telégrafo, a fotografia, navegação a vapor e o sistema ferroviário" (MARX, 2013, p. 517).

Nota-se, por conseguinte, que a ideia de capital industrial postulada por Marx pode ser considerada precursora de noções que só foram efetivamente difundidas algumas décadas mais tarde, a exemplo das noções de agroindústria e indústria de serviços (SANTOS, 2013).

Conforme enfatiza Bolaño (2000), no Livro II de O Capital, Marx é ainda mais explícito ao descrever a "indústria de transportes" plenamente inserida na lógica de produção de valor típica do capitalismo, ainda que produza um efeito útil (o deslocamento de lugar) que "só pode ser consumido durante o processo de produção" (MARX, 2014, p. 134).

\footnotetext{
O que a indústria dos transportes vende é o próprio deslocamento de lugar. $O$ efeito útil obtido é indissoluvelmente vinculado ao processo de transporte, isto é, ao processo de produção da indústria dos transportes. [...] Mas o valor de troca desse efeito útil é determinado, como o de toda e qualquer mercadoria, pelo valor dos elementos de produção nele consumidos (força de trabalho e meios de produção) acrescido do mais-valor criado pelo maistrabalho dos trabalhadores ocupados na indústria dos transportes (MARX, 2014, p. 133-134).
}

Tendo em vista que, na indústria de transporte, "se paga o próprio processo de produção, e não um produto dele separado" (MARX, 2014, p. 134), o autor emprega uma fórmula para representar a indústria de transporte, em que a mercadoria $M$ ' está ausente:

$$
\mathrm{D}-\mathrm{M}<_{\mathrm{MP}}^{\mathrm{T}} \ldots \mathrm{P}-\mathrm{D}^{\prime}
$$

Mas essa ausência da mercadoria $M$ ' não é um impedimento para que o autor indique aí a presença do capital industrial, "o único modo de existência do capital em que este último tem como função não apenas a apropriação de mais-valor ou de maisproduto, mas também sua criação" (MARX, 2014, p. 134).

Além dos exemplos da mercadoria força de trabalho, do capital industrial e da indústria de transporte, vale a pena destacar que Marx considera que o próprio capital se torna uma "mercadoria sui generis" quando assume a forma de "capital portador de juros" (MARX, 2017, p. 385-386), uma "mercadoria de tipo específico" que não é vendida, mas emprestada (MARX, 2017, p. 396-397). Nota-se que, mais uma vez, estamos diante de um uso da noção de mercadoria por analogia e extensão da ideia primeiramente apresentada. 
Sob a forma do capital portador de juros, o dinheiro gera mais dinheiro (D-D') "sem a mediação do processo de produção e circulação". O capital portador de juros é "dinheiro que engendra mais dinheiro, valor que valoriza a si mesmo" sem passar pelas metamorfoses do ciclo completo do capital. Com o capital portador de juros, a relação capitalista assume sua forma "mais fetichista", quando viceja a ilusão de que "criar valor torna-se uma qualidade do dinheiro". Surge o fetiche do capital "em toda a sua pureza", isto é, a "mistificação capitalista em sua forma mais descarada". O fetiche do capital é o "fetiche automático do valor que se valoriza a si mesmo, do dinheiro que gera mais dinheiro, mas que, ao assumir essa forma, não traz nenhuma cicatriz de seu nascimento" (MARX, 2017, p. 441-443).

As críticas daqueles que acusam Marx de ser um teórico "industrialista” e de não ter incorporado o trabalho intelectual na sua análise ignoram também outros trechos da sua obra em que o autor expõe exatamente o contrário. Marx deixou relevantes registros sobre o trabalho envolvido na produção de mercadorias que não têm materialidade corpórea. Esses registros podem ser encontrados principalmente nos manuscritos Teorias da Mais-valia - Vol. I (MARX, 1980a) e Capítulo VI inédito de O Capital (MARX, 2004).

Alguns desses trechos merecem ser citados. Mas, antes, é necessário esclarecer que o autor emprega um conceito de serviço diferente da acepção empregada atualmente. Para ele, serviço é algo comprado para consumo do seu valor de uso e não para que funcione como capital variável, fator vivo que produz valor e mais-valia. Em seus termos, "um serviço nada mais é do que o efeito útil de um valor de uso, seja da mercadoria, seja do trabalho" (MARX, 2013, p. 269). Nesse sentido específico, Marx classifica o serviço como trabalho improdutivo e seu executor como trabalhador improdutivo, uma vez que "seu trabalho é consumido por causa do seu valor de uso e não como trabalho que gera valores de troca; é consumido improdutivamente" (MARX, 2004, p. 111). No entanto, segundo o autor, quando esse tipo de atividade está subordinado ao comando de um empresário com o objetivo de produzir valor e mais-valia, trata-se de "trabalho produtivo" no sentido especificamente capitalista do termo. ${ }^{2}$

Ao discutir a produção "imaterial” (MARX, 1980a, p. 403) e "não material” (MARX, 2004, p. 119) ${ }^{3}$, o autor classifica como produtivo o trabalho eminentemente intelectual de um escritor, "que fornece um trabalho industrial [Arbeit Fabrik] ao seu editor", uma vez que a produção desse "literato proletário [...], que produz livros [...] por encargo do seu editor, [...] está subordinada ao capital e só é levada a cabo para valorizar este último" (MARX, 2004, p. 115).

\footnotetext{
${ }^{2}$ Marx (1980a, 2004, 2013) distingue o conceito de trabalho produtivo na acepção geral (trabalho universal, independentemente das suas formas históricas) e na acepção válida no contexto histórico do modo de produção capitalista. No primeiro caso, trabalho produtivo é o que cria valores de uso para satisfazer as necessidades humanas. No segundo caso, trabalho produtivo é o que cria valor e a maisvalia a ser apropriada pelo capitalista (MARQUES, 2015, 2018).

${ }^{3} \mathrm{Na}$ versão original do manuscrito conhecido como Teorias da Mais-valia (Theorien Uber Den Mehrwert), Marx emprega a expressão em alemão "immateriellen Produktion" (MARX, 1965, p. 1329), que foi vertida para o português como "produção imaterial” (MARX, 1980a, p. 403) e para o inglês como "non-material production" (MARX, 1994, p. 143). Na versão original do manuscrito conhecido como Capítulo VI inédito de O Capital (Resultate des unmittelbaren Produktionsprozesses), o autor adota a expressão "nicht materiellen Produktion" (MARX, 1969, p. 69), traduzida para o português como "produção não material” (MARX, 2004, p. 119) e para o inglês como "non-material production" (MARX, 1994, p. 451).
} 
Nessas mesmas passagens, o autor aborda alguns tipos de trabalhos cujos produtos só podiam, no tempo de Marx, ser consumidos durante o ato da produção, a exemplo das atividades do cantor e do professor (mestre-escola). Conforme aponta Marx, esse tipo de trabalho é passível de ser alcançado pela lógica da produção capitalista, e seu executor pode ser considerado trabalhador produtivo, isto é, trabalhador produtor de valor e de mais-valia (MARQUES, 2015, 2018). Essa perspectiva marxiana está fundamentada no pressuposto de que produção de maisvalia é "o fim determinante, o interesse propulsor e o resultado final do processo de produção capitalista" (MARX, 2004, p. 41). Em outras palavras, "a produção capitalista não é apenas produção de mercadorias, mas essencialmente produção de mais-valia" (MARX, 2013, p. 578).

É bastante reveladora uma conhecida passagem do Livro I de O Capital, em que Marx (2013, p. 578), ao tratar de um exemplo "fora da esfera da produção material", explica, de maneira ácida e irônica, que a escola pode assumir o caráter de um empreendimento capitalista, em que os professores, tal qual operários, produzem o valor e a mais-valia a ser apropriada pelo patrão:

Se nos for permitido escolher um exemplo fora da esfera da produção material, diremos que um mestre-escola é um trabalhador produtivo se não se limita a trabalhar as cabeças das crianças, mas exige trabalho de si mesmo até o esgotamento, a fim de enriquecer o patrão. Que este último tenha investido seu capital numa fábrica de ensino, em vez de numa fábrica de salsichas, é algo que não altera em nada a relação (MARX, 2013, p. 578).

Nota-se nessa passagem que Marx antecipa alguns fenômenos capitalistas que apenas existiam em germe no século XIX, mas que se expandem cada vez mais na atualidade: a indústria capitalista da Educação, o conhecimento transformado em mercadoria, os grandes conglomerados empresariais que se digladiam na arena do mercado educacional e a "instituição que trafica com o conhecimento" (MARX, 2004, p. 115$)^{4}$

Retornemos mais uma vez ao Livro I de O Capital, onde Marx nos apresenta uma definição de "trabalho produtivo" que não se limita à produção manual imediata, mas inclui também qualquer uma das subfunções do "trabalhador coletivo", ou seja, do conjunto de trabalhadores que tomam parte no processo de produção e que executam atividades que exigem diferentes tipos de habilidades e qualificações, inclusive aquelas que não são eminentemente manuais. Conforme explica Marx, com o desenvolvimento do modo de produção especificamente capitalista, quando a produção deixa de ser um ato isolado do trabalhador e atinge grande escala, mobilizando um grande contingente de trabalhadores que atuam de maneira coordenada, o produto direto do produtor individual se transforma

num produto social, no produto comum de um trabalhador coletivo, isto é, de um pessoal combinado de trabalho, cujos membros se encontram a uma distância maior ou menor do manuseio do objeto de trabalho. [...] Para trabalhar produtivamente, já não é mais necessário fazê-lo com suas próprias

\footnotetext{
${ }^{4}$ Ainda que esse presságio de Marx tenha se tornado hoje uma realidade evidente, discursos pósmodernistas postulam que as reflexões de Marx seriam pouco úteis atualmente, quando supostamente estaríamos vivendo uma sociedade pós-industrial (LAZZARATO, 1996), uma economia do conhecimento (GORZ, 2003) ou uma espécie de capitalismo cognitivo (MOULIER-BOUTANG, 2011).
} 
mãos; basta, agora, ser um órgão do trabalhador coletivo, executar qualquer uma das suas subfunções (MARX, 2013, p. 577).

Nota-se, por conseguinte, que Marx atribui uma unidade dialética ao trabalhador coletivo ao descrevê-lo como um organismo social responsável tanto pelas atividades laborais eminentemente manuais, quanto por aquelas essencialmente intelectuais. No Capítulo VI inédito de O Capital, o autor é ainda mais explícito ao discutir a produção fabril em larga escala e o conjunto complexo e heterogêneo de trabalhadores que nela atua. Nesse contexto, Marx afirma que no trabalhador coletivo estão incluídas "diversas capacidades de trabalho que cooperam e formam a máquina produtiva total", a exemplo dos sujeitos que trabalham "como diretor (manager), engenheiro (engineer), técnico etc., [...] como capataz (overlooker), [...] como operário manual ou até como simples servente", sendo todos esses ofícios "diretamente explorados pelo capital e subordinados em geral a seu processo de valorização e de produção". ${ }^{5}$

Em suma, podemos afirmar que os autores que confinam o arcabouço teórico de Marx aos limites do trabalho manual e da produção de bens tangíveis ignoram alguns fundamentos centrais da construção teórica do autor alemão. As perspectivas que relacionam a teoria de Marx a essa noção tão limitada de industrialismo não encontram fundamentação em seus textos. $\mathrm{O}$ vigoroso estudo feito por Marx para compreender as tendências e leis do capital não se limita à produção fabril-material (AMORIM, 2018).

Diante desse ponto de vista, passemos a outras questões: teria Marx enfrentado o enigma do valor no caso das criações do intelecto humano cujo tempo de reprodução é nulo? Como Marx incorporou em sua análise as situações em que o tempo de reprodução de uma mercadoria é menor se comparado com o tempo necessário para sua concepção e desenvolvimento original?

\section{TEMPO DE PRODUÇÃO E TEMPO DE REPRODUÇÃO, SEGUNDO MARX}

Ao refletir sobre as atividades desenvolvidas no campo da ciência, que o autor considerava ser um "produto geral do desenvolvimento social” (MARX, 2004, p. 93), ele reconheceu a diferença entre tempo de trabalho necessário para reproduzir um conhecimento previamente desenvolvido e o tempo despendido durante seu desenvolvimento original. Ou seja, Marx buscou decifrar a esfinge do valor no campo do conhecimento e da ciência. No manuscrito Teorias da Mais-Valia - Vol. I, ele afirmou que

o produto do trabalho intelectual - a ciência - está sempre muito abaixo do valor. É que o tempo de trabalho necessário para reproduzi-la não guarda em absoluto proporção alguma com o tempo de trabalho requerido pela produção original. Um colegial, por exemplo, pode aprender em uma hora o teorema do binômio (MARX, 1980a, p. 339).

\footnotetext{
5 Observa-se que Marx não incorre em dois desacertos presentes em abordagens pós-modernistas contemporâneas, como, por exemplo, nas concepções de Lazzarato (1996), Gorz (2005) e MoulierBoutang (2011): (i) o equívoco da distinção dicotômica entre trabalho manual e trabalho cognitivo, como se fosse possível existir trabalho mental apartado de esforço físico; (ii) a ilusão de que, nas dinâmicas capitalistas da atualidade, somente o trabalho cognitivo, não mais o trabalho físico, seria o elemento responsável pela criação de valor.
} 
No Livro I de O Capital, como desdobramento dessa constatação, o autor alega que não existe custo para o capitalista quando "a ciência "alheia" é incorporada ao capital como trabalho alheio" (MARX, 2013, p. 460).

Uma vez descobertas, a lei que regula a variação da agulha magnética no campo de ação de uma corrente elétrica ou a lei da indução do magnetismo no ferro, em torno do qual circula uma corrente elétrica, já não custam mais um só centavo (MARX, 2013, p. 460).

No Livro III de O Capital, Marx introduz a ideia de "trabalho geral" (2017, p. 133) ou "trabalho universal" (1980c, p.116) ${ }^{6}$ para enfatizar que as aplicações da ciência e das inovações aos processos produtivos são fruto de um esforço coletivo que envolve, não só o trabalho vivo do trabalhador coletivo, mas também os trabalhos antecessores:

Trabalho geral é todo trabalho científico, toda descoberta, toda invenção. Ele é condicionado, em parte, pela cooperação com o trabalho vivo, em parte, pela utilização dos trabalhos anteriores (MARX, 2017, p. 133).

A seguir, ele destaca a diferença entre os custos de se produzir pela primeira vez um novo equipamento e os custos de reproduzi-lo depois de ele ter sido previamente concebido. Marx afirma que frequentemente se observam:

1. A grande diferença nos custos entre a primeira construção de uma nova máquina e sua reprodução [...].

2. Os custos muito mais altos com os quais geralmente se administra um estabelecimento baseado em novas invenções, comparados aos dos estabelecimentos posteriores, erguidos sobre suas ruínas, ex suis ossibus [de seus ossos]. Isso chega a tal ponto que, na maioria, os primeiros empresários vão à bancarrota, e só florescem os posteriores, aqueles a cujas mãos chegam mais baratos os edifícios, a maquinaria etc. Por essa razão, na maior parte das vezes é a espécie mais reles e miserável de capitalistas monetários que extrai o maior lucro de todos os novos desenvolvimentos do trabalho geral do espírito humano e de sua aplicação social mediante o trabalho combinado (MARX, 2017, p. 133).

Percebe-se que, no alto nível de abstração da argumentação dos capítulos iniciais do Livro I de O Capital, a magnitude do valor da mercadoria deriva do seu processo de produção. Porém, na medida em que a exposição avança em direção a níveis mais concretos de análise, o valor da mercadoria passa a ser apresentado como fruto do

\footnotetext{
${ }^{6}$ Na versão em alemão, Marx (1964) emprega a expressão "Allgemeine Arbeit", que foi vertida para o inglês como "universal labor" (MARX, 1998). É possível perceber uma inter-relação entre a noção de "trabalho universal" (MARX, 1980c, p. 116) ou "trabalho geral" (MARX, 2017, p. 133) e a noção de "general intellect", que Marx (2011, p. 589) adota nos manuscritos conhecidos como Grundrisse. Rosdolsky (2001, p. 584) corrobora essa interpretação ao afirmar que "na terminologia marxiana (isso vale especialmente para o jovem Marx), o conceito de Allgemeine (comum, geral, universal) não é idêntico ao de Gemeinschaftlichen (comunitário, social). Ao contrário, designa aquele que, em uma sociedade de proprietários privados atomizados, surge da colisão entre o interesse comunitário e o particular".
} 
processo de reprodução, não de produção. Quando a reprodução do capital é explicitamente introduzida na discussão, Marx alega que o que o determina o valor de qualquer mercadoria não é o tempo de trabalho socialmente necessário para sua produção, mas, sim, o tempo de trabalho socialmente necessário para sua reprodução. No entanto, parte da tradição marxista tem desconsiderado esse aspecto fundamental da teoria do valor ao pôr foco exclusivamente nos primeiros capítulos do Livro I de O Capital (ROTTA, TEIXEIRA, 2019).

Nos termos de Marx,

O valor das mercadorias é determinado não pelo tempo de trabalho que sua produção custou originalmente, mas pelo tempo de trabalho que custa sua reprodução, tempo este que diminui continuamente em consequência do desenvolvimento da força produtiva social do trabalho (MARX, 2017, p. 448).

Ao transpor essa perspectiva para a produção de máquinas, o autor introduz a ideia de "depreciação moral" (2013, p. 477) ou "desgaste moral" (2014, p. 269). Esse tipo de depreciação, que representa a desvalorização de máquinas existentes, decorre do fato de que, com o passar do tempo, máquinas similares às já existentes passam a ser reproduzidas com menores custos. Além disso, são desenvolvidas máquinas melhores, que se tornam concorrentes das mais antigas, ainda que estas estejam em bom estado.

[...] além do desgaste material, a máquina sofre, por assim dizer, um desgaste moral. Ela perde valor de troca na medida em que máquinas de igual construção podem ser reproduzidas de forma mais barata, ou que máquinas melhores passam a lhe fazer concorrência. Em ambos os casos, seu valor, por mais jovem e vigorosa que a máquina ainda possa ser, já não é determinado pelo tempo de trabalho efetivamente objetivado nela mesma, mas pelo tempo de trabalho necessário à sua própria reprodução ou à reprodução da máquina aperfeiçoada. É isso que a desvaloriza, em maior ou menor medida. Quanto mais curto o período em que seu valor total é reproduzido, tanto menor o perigo da depreciação moral, e quanto mais longa a jornada de trabalho, tanto mais curto é aquele período (MARX, 2013, p. 477)

Essa compreensão que o autor descreve ao abordar a maquinaria também é aplicada por ele às edificações e ao capital fixo em geral:

Quando a maquinaria, as edificações, ou seja, o capital fixo em geral alcançou certa maturidade [...], uma desvalorização similar ocorre em consequência de aperfeiçoamentos nos métodos de reprodução desse capital fixo. $\mathrm{O}$ valor da maquinaria etc. diminui, então, não porque ela é substituída ou desvalorizada em certo grau por uma maquinaria mais nova, mais produtiva etc., mas porque ela passou a ser reproduzida por um preço menor" (MARX, 2017, p. 144).

De maneira similar, o autor alega que o valor da mercadoria força de trabalho também está submetido ao mesmo princípio: "como no caso de qualquer outra mercadoria, a força de trabalho tem seu valor determinado pela quantidade de trabalho necessária à sua reprodução". E a seguir reforça: "no caso do salário, por ser ele o valor de sua mercadoria, a força de trabalho, [...] tal valor é determinável (como o de qualquer outra mercadoria) pelo trabalho necessário à reprodução dessa mercadoria" (MARX, 2014, p. 483-484). 


\section{CONSIDERAÇÕES FINAIS}

Conforme explica Rosdolsky (2011), as categorias econômicas expostas por Marx representam relações sociais reais. Elas não foram deduzidas por um tratamento estritamente lógico, mas também pela análise do desenvolvimento histórico da sociedade. Suas deduções lógicas são apresentadas em paralelo com suas deduções históricas. Os resultados da sua análise abstrata são confrontados com o efetivo desenvolvimento histórico. Nas palavras de Marx (2011, p. 58), as categorias são "produtos de relações históricas e têm sua plena validade só para essas relações e no interior delas".

No mundo em que vivemos hoje, assistimos a fenômenos que não existiam no século XIX ou existiam em estado embrionário. Bons exemplos são o desenvolvimento das tecnologias de informação e comunicação que conformam a Internet, bem como a ampliação e a diversificação da produção de mercadorias intangíveis. A constatação dessa realidade enseja a pergunta: no contexto histórico contemporâneo, o arcabouço teórico de Marx perdeu seu caráter explicativo?

Ao analisarmos a realidade histórica atual, devemos renovar sempre o compromisso com a crítica e com a dúvida como forças de construção da ciência e, em última instância, como instrumentos de apreensão do mundo contemporâneo. Esse exercício exige desenvolver novas reflexões para além dos limites impostos pelo momento histórico vivido por Marx. Esse tem sido e deve continuar a ser o esforço da tradição marxista. No entanto, em resposta à pergunta colocada, entendo que não devemos descartar o arcabouço teórico marxiano, pois ele contempla, de maneira reveladora e inspiradora, o trabalho intelectual, a mercadoria intangível e as relações sociais ocultas pelo seu fetichismo.

Um dos legados de Marx foi seu compromisso permanente com a crítica bem fundamentada como caminho para superar análises que se limitam às manifestações fenomênicas da realidade e que não atingem suas essências contraditórias. $O$ autor rejeitava a crítica preconceituosa da opinião pública, mas tinha grande apreço pela crítica científica. Quando do lançamento da primeira edição de O Capital, ele registrou no prefácio da obra:

Todos os julgamentos fundados numa crítica científica serão bemvindos. Diante dos preconceitos da assim chamada opinião pública, à qual nunca fiz concessões, tomo por divisa, como sempre, o lema do grande florentino: Segui il tuo corso, e lascia dir le genti! [Segue o teu curso e deixa a gentalha falar!] (MARX, 2013, p. 81).

Artigo recebido em 05/02/2020 e aprovado em 23/04/2020.

\section{REFERÊNCIAS}

ALBAGLI, S.; MACIEL, M. L. (org.). Informação, Conhecimento e Poder, mudança tecnológica e inovação social. Rio de Janeiro: Garamond, 2011.

AMORIM, H. Trabalho imaterial - Marx e o debate contemporâneo. São Paulo: Annablume, $2^{\mathrm{a}}$ ed., 2018.

ANTUNES, R. O privilégio da servidão: o novo proletariado de serviços na era digital. São Paulo: Boitempo, 2018. 
BEZERRA, A. C.; SCHNEIDER, M.; PIMENTA, R. M.; SALDANHA, G. S. iKRITIKA: estudos críticos em informação. Rio de Janeiro: Garamond, 2019.

BOLAÑO, C. R. S. Indústria cultural, informação e capitalismo. São Paulo: Hucitec, 2000.

COCCO, G.; ALBAGLI, S. (org.). Revolução 2.0 e a Crise do Capitalismo Global. Rio de Janeiro: Garamond, 2012.

COTRIM, V. Trabalho produtivo em Karl Marx: velhas e novas questões. São Paulo: Alameda, 2012.

DANTAS, M. Trabalho com informação: valor, apropriação, acumulação nas redes do capital. Rio de Janeiro: UFRJ, 2012.

FOLEY, D. Mercadoria. In: BOTTOMORE, T. (org.) Dicionário do Pensamento Marxista. Rio de Janeiro: Zahar, 2001.

GORZ, A. O Imaterial, Conhecimento, Valor e Capital. São Paulo: Annablume, 2005.

KOSIK, K. A dialética do concreto. Rio de Janeiro: Paz e Terra, 1976.

LAZZARATO, M. Immaterial labour. In: VIRNO, P., HARDT, M. (org.). Radical thought in Italy. Minneapolis: University of Minnesota Press, 1996.

LESSA, S. Centralidade ontológica do trabalho e centralidade política proletária. Lutas Sociais, n.13-14, p. 106-121, 2005.

LESSA, S. Trabalho e proletariado no capitalismo contemporâneo. $2^{\text {a }}$ ed. São Paulo: Cortez, 2011.

MACHADO, G. H. L. Trabalho produtivo e improdutivo: a mercadoria. 20 out. 2015. Disponível em: http://blog.esquerdaonline.com/?p=5754. Acesso: 10 abr. 2020.

MANDEL. E. El Capital: cien años de controversias en torno de la obra de Karl Marx. México: Siglo XXI, 1985.

MARQUES, R. M. Trabalho, informação e conhecimento: relendo Marx na era da informação. Logeion: Filosofia da Informação, v. 2, p. 47-71, 2015.

MARQUES, R. M. Trabalho e valor nas mídias sociais: uma análise sob as lentes do marxismo. Trabalho \& Educação, v. 27, p. 111-130, 2018.

MARQUES, R. M.; RASLAN, F.; MELO, F.; KERR PINHEIRO, M. M. (org.). A informação e o conhecimento sob as lentes do marxismo. Rio de Janeiro: Garamond, 2014.

MARX, K. Das Kapital - Kritik der politischen Ökonomie, Dritter Band, Buch III: In: MARX, K; ENGELS, F. Werke, Vol. 25, Berlin: Dietz Verlag, 1964.

MARX, K. Theorien Uber Den Mehrwert. In: In: MARX, K.; ENGELS, F. Werke, Vol. 26, Berlin: Dietz Verlag, 1965.

MARX, K. Resultate des unmittelbaren Produktionsprozesses. Das kapital. I Buch. Der Produktionsprozess des Kapitals. VI Kapitel. Frankfurt: Verlag Neue Kritik, 1969.

MARX, K. Teorias da Mais-valia - História crítica do pensamento econômico. Vol. I. Rio de Janeiro: Civilização Brasileira, 1980a.

MARX, K. O Capital, Livro I. Vol. 1, Rio de Janeiro: Civilização Brasileira, 1980b.

MARX, K. O Capital, Livro III, Vol. 4, Rio de Janeiro: Civilização Brasileira, 1980c. 
MARX, K. Economic works 1861-1863, Economic manuscript of 1861-63 (conclusion), A contribution to the critique of political economy. In: MARX, K.; ENGELS, F. Collected Works, Vol. 34, London: Lawrence \& Wishart, 1994.

MARX, K. Capital - A Critique of Political Economy - Volume III. In: MARX, K.; ENGELS, F. Collected Works, Vol. 37, London: Lawrence \& Wishart, 1998.

MARX, K. Contribuição à Crítica da Economia Política, São Paulo: Martins Fontes, 2003.

MARX, K. Capítulo VI inédito de O Capital - Resultados do Processo de Produção Imediata, $2^{\text {a }}$. ed. São Paulo: Centauro, 2004.

MARX, K. Para a crítica da economia política, Manuscrito de 1861-1863, Cadernos I a V, Terceiro Capítulo - O capital em geral. Belo Horizonte: Autêntica Editora, 2010.

MARX, K. Grundrisse. São Paulo: Boitempo, 2011.

MARX, K. O Capital, Livro I. São Paulo: Boitempo, 2013.

MARX, K. O Capital, Livro II. São Paulo: Boitempo, 2014.

MARX, K. O Capital, Livro III. São Paulo: Boitempo, 2017.

MOHUN, S. Valor. In: BOTTOMORE, T. (org.) Dicionário do Pensamento Marxista. Rio de Janeiro: Zahar, 2001.

MOULIER-BOUTANG, Y. Cognitive Capitalism. London: Polity Press, 2011.

PAULA, J. A. Ensaio sobre a atualidade da lei do valor. Revista de Economia Política, v. 4, n. 2, 1984.

PRADO, E. F. S. Uma crítica à economia política do imaterial de André Gorz. Outubro Revista do Instituto de Estudos Socialistas, n. 11, p. 45-70, 2004.

ROSDOLSKY, R. Gênese e estrutura de O Capital de Karl Marx. Rio de Janeiro: Contraponto, 2001.

ROTTA, T. N., TEIXEIRA, R. A. The commodification of knowledge and information. In: VIDAL, M.; SMITH, T.; ROTTA, T.; PREW, P. (org.). The Oxford Handbook of Karl Marx. New York: Oxford University Press, 2019.

RUBIN, I. I. A teoria marxista do valor. São Paulo: Polis, 1987.

SANTOS, V. O. Trabalho imaterial e teoria do valor em Marx. São Paulo: Expressão Popular, 2013.

SCHNEIDER, M. A dialética do gosto: informação, música e política. Rio de Janeiro: Circuito, 2015. 